This item was submitted to Loughborough's Research Repository by the author.

Items in Figshare are protected by copyright, with all rights reserved, unless otherwise indicated.

\title{
Effects of intake-port throttling on combustion behaviour in diesel low- temperature combustion
}

\section{PLEASE CITE THE PUBLISHED VERSION}

https://doi.org/10.1177/1468087417732881

PUBLISHER

SAGE @ IMechE

VERSION

AM (Accepted Manuscript)

\section{PUBLISHER STATEMENT}

This work is made available according to the conditions of the Creative Commons Attribution-NonCommercial 4.0 International (CC BY-NC 4.0) licence. Full details of this licence are available at: http://creativecommons.org/licenses/by-nc/4.0/

\section{LICENCE}

CC BY-NC 4.0

\section{REPOSITORY RECORD}

Sogbesan, Oluwasujibomi, Colin P. Garner, and Martin H. Davy. 2019. "Effects of Intake-port Throttling on Combustion Behaviour in Diesel Low-temperature Combustion". figshare. https://hdl.handle.net/2134/27777. 


\title{
Effects of intake-port throttling on combustion behaviour in diesel low temperature combustion (LTC)
}

\section{FINAL DRAFT - POST REFEREEING}

\author{
Oluwasujibomi Sogbesan, Colin P. Garner and Martin H. Davy
}

September 5, 2017

\begin{abstract}
This paper describes the effects of intake-port throttling on diesel low temperature combustion (LTC) at a low and medium load condition. These conditions were known for their characteristically high hydrocarbon (HC) emissions predominantly from over-mixed and under-mixed mixture zones respectively. The investigation was carried out to supplement current findings in literature with valuable information on the formation of $\mathrm{HC}$ emissions with increasing swirl levels generated by intake-port throttling. This was achieved through the use of cycle-resolved HC measurements in addition to cycle averaged emissions and in-cylinder pressure-derived metrics. While there was negligible overall effect at the moderately-dilute lowload conditions, increasing swirl has been shown to be beneficial to premixing efficacy under highly dilute conditions with extended ignition delay. This potential advantage was found to be nullified by the swirlinduced confinement of fuel and combustion products to the central region of the cylinder leading to poor late cycle burn rates and increased smoke emissions. $\mathrm{HC}$ emissions from the squish and head quench regions were reduced by an increase in swirl ratio.
\end{abstract}

\section{Introduction}

Swirl, as defined by Heywood [1], is the rotation of the in-cylinder charge about the axis of the cylinder.
The presence of substantial swirl motion is brought about through the deliberate design of the engine intake system and combustion chamber geometry.

The main benefit of inducing swirl is to enhance fuel-air mixing in the cylinder beyond that offered by a comparable quiescent system. Swirl generation represents a trade-off of pressure drop in the inlet system for increased flow kinetic energy and mixing enhancement. Due to the interactions between multiple parameters of a combustion engine, the effects of swirl are largely influenced by the specific engine operating conditions being investigated. The commonly observed benefits of swirl include improved mixing efficacy, enhanced evaporation of wetted surfaces, increased early air entrainment and late cycle turbulence. Negative effects of swirl have also been investigated, these include increased heat loss to cylinder walls and reduced volumetric efficiency [2].

Induced swirl tends to be commonplace in small to medium sized DI diesel engines that have to maintain mixing efficacy despite a decrease in the number of injector nozzle holes and absolute injection pressure compared to larger bore engines. Swirl optimisation has been investigated for advanced diesel combustion strategies due to the need for rapid premixing at highly dilute conditions. Modulated Kinetics (MK) [3], a form of late injection LTC, utilises enhanced swirl to ensure rapid mixing and combustion of fuel injected during the expansion stroke of the combustion cycle. A study on the effects of increased swirl 
on this particular LTC strategy showed that late cycle mixing was enhanced regardless of engine load, but also that this benefit had to be offset against the increased heat loss and lower work conversion efficiency [4]. The resulting optimised swirl value promoted good premixing, desirable heat release characteristics and sustained high soot oxidation rates later in the combustion event.

Kook et al.. [5] studied the effects of swirl on carbon monoxide (CO) formation in early-injection LTC and found an optimal swirl ratio of 2.5 (the range tested was $1.44-7.12$ ) with $\mathrm{CO}$ emissions markedly increasing for any further increase in swirl. Numerical models employed in this study predict that swirl vortices created at moderate swirl ratios confine partially burned fuel within the bowl resulting in poor utilisation of squish area oxygen. There was also a derived increase in heat loss due to the increased swirl resulting in lower overall fuel conversion efficiency.

Opat et al. [6] also observed the late cycle burn to be slower for elevated swirl cases in early-injection LTC, attributing this to the same phenomenon described by Kook [5] regarding the vortex induced confinement of partially burned fuel within the bowl. However, for late injection LTC Choi et al. [4] noted a reversal of this trend. Late cycle burn times, although initially decreased with increasing swirl, were found to increase at the highest swirl ratios. Although this behaviour was not explained in the paper, it is thought to be due, at least in part, to the differences in flow structures and crank angle timing positions (for premixed and mixing controlled burn) for late injection LTC compared to early injection LTC. The effects of swirl on the overall combustion efficiency are also discussed in these prior studies but the direct effects of swirl on hydrocarbon (HC) emissions have not been extensively investigated in literature. This is significant as, in addition to $\mathrm{CO}$, hydrocarbon species form the bulk of 'unburned' gases for a low smoke/low oxides of nitrogen (NOx) LTC condition with poor combustion efficiency.

The purpose of the present study is to gain an understanding of the influence of intake-port throttle induced swirl on $\mathrm{HC}$ emissions in LTC. It was anticipated that there will be significant changes in the quantity and in-cylinder location of $\mathrm{HC}$ species
Table 1: Engine, injection system and fuel specifications

\begin{tabular}{ll}
\hline Property & Description \\
\hline Engine & AVL 5402 Single Cylinder Diesel \\
Displaced volume & 0.51 litre \\
Bore x Stroke & $85 \mathrm{~mm} \times 90 \mathrm{~mm}$ \\
Compression ratio & $17.1: 1$ \\
Rated Speed & $4200 \mathrm{r} / \mathrm{min}$ \\
Maximum Power & $16 \mathrm{~kW}$ \\
Nominal Swirl Ratio & 1.78 \\
Combustion Chamber & Re-entrant Bowl \\
Intake Ports & Tangential and Swirl \\
Intake valves open & $8{ }^{\circ} \mathrm{CA} \mathrm{BGTDC}$ \\
Intake valves closed & $226^{\circ} \mathrm{CA} \mathrm{AGTDC}$ \\
Exhaust valves open & $128{ }^{\circ} \mathrm{CA}$ ATDC \\
Exhaust valves closed & $18{ }^{\circ} \mathrm{CA} \mathrm{AGTDC}$ \\
Injection System & Bosch Common Rail \\
Nozzle Type & $\mathrm{Valve} \mathrm{Covered} \mathrm{Orifice} \mathrm{(VCO)}$ \\
Injector holes / Diameter & $5 / 0.18 \mathrm{~mm}$ \\
Fuel Density (@ 15 $\left.{ }^{\circ} \mathrm{C}\right)$ & $840 \mathrm{~kg} \cdot \mathrm{m}^{-3}$ \\
PAH Content & $9 \%$ \\
Sulphur Content & $8 \mathrm{mg} \cdot \mathrm{kg}{ }^{-1}$ \\
Cetane Number & 52 \\
\hline
\end{tabular}

which may help to supplement the current knowledge on $\mathrm{CO}$ formation and overall combustion efficiency trends. In addition, the potential of increased incylinder mixing to extend the rather narrow boundaries $[7,8]$ of acceptable LTC combustion (particularly with respect to soot emissions) are investigated.

\section{Experimental set-up}

The engine used in this work was a single cylinder version of a 2 litre light duty direct injection (DI), 4cylinder diesel engine. An automotive grade low sulphur diesel fuel (sulphur content $<10 \mathrm{mg} / \mathrm{kg}$ ) that met the current British Standard BS EN 590 was used. Further details of the engine specification, fuelling system and fuel used are provided in Table 1.

The research engine facility, which has been fully described and illustrated schematically in a number of previous works from the authors' research group $[9,10,7,8,11]$, was instrumented with the provision to measure boosted intake air temperature and 
pressure, fuel and air flow rates, and in-cylinder pressure. Intake pressure was measured using Kistler 4045A5 piezo-resistive pressure transducer while the in-cylinder pressure was measured with a piezoelectric AVL QC34C flush-mounted water-cooled transducer. These pressure readings were logged at a resolution of 0.5 crank angle (CA), averaged over a minimum of 200 consecutive engine cycles and then used to derive the related combustion parameters such as gross indicated mean effective pressure (GIMEP) and apparent (net) heat release rate (AHRR).

For the purposes of this investigation, in-cylinder swirl levels were varied by throttling the direct and tangential ports of the engine intake manifold. Figure 1 details the throttling arrangements. A standardised steady flow test procedure was performed to calculate the AVL swirl ratio for a given intake manifold port configuration [12].

The engine was maintained at the desired speed by a motoring dynamometer. Hence for the constant fuelling quantity employed in this study, variations in engine load are a direct indication of combustion quality due to changes in input variables. Fuelling parameters (injection pressure, timing, number of multiple injections and injection quantity) were fully and independently controllable using an ETAS INCA ${ }^{\mathrm{TM}}$ engine controller.

The fuel consumption rate was measured by an AVL 733 dynamic gravimetric fuel meter. Emissions measurements for $\mathrm{CO}, \mathrm{CO}_{2}, \mathrm{THC}, \mathrm{NOx}$ and $\mathrm{O}_{2}$ in the exhaust were conducted using a Horiba MEXA 7100HEGR emission analyser. Emissions and flow rate measurements were logged at a frequency of $1 \mathrm{~Hz}$ over a duration of at least 2 minutes per test point. Filter smoke number (FSN) values were measured using an AVL 415 smoke meter.

\subsection{Cycle resolved hydrocarbon mea- surement}

In order to obtain cycle resolved hydrocarbon emissions, a fast flame ionisation detector (Cambustion HFR 400 fast-FID) was positioned in the exhaust port giving near-instantaneous measurements of $\mathrm{HC}$ concentration. The slow response time of a conventional FID when measuring wet UHC is due mainly

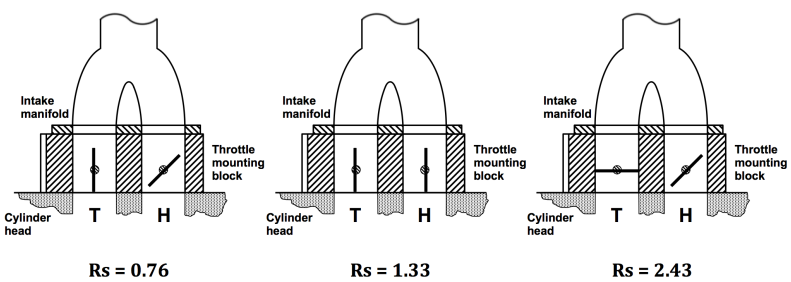

Figure 1: Schematic illustration of throttling arrangement and swirl flap positions for the three AVL swirl ratios examined, $\mathrm{T}=$ Tangential port, $\mathrm{H}=\mathrm{He}-$ lical port

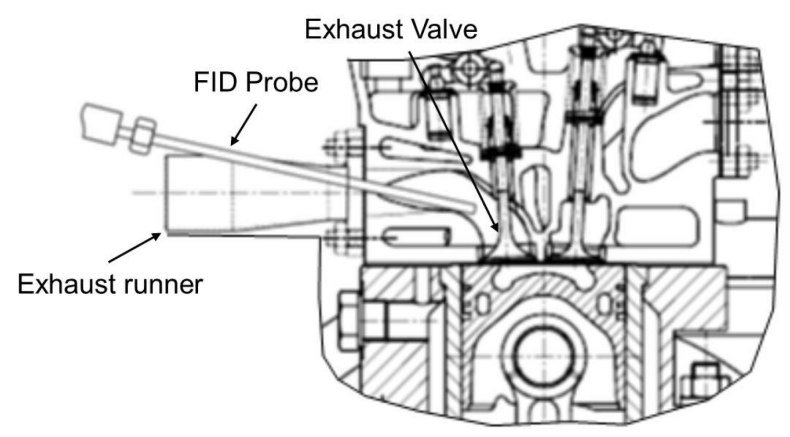

Figure 2: Cross-section though exhaust manifold and cylinder head detailing the positioning of the fast FID probe within the exhaust port with respect to the exhaust valve

to sample handling i.e. sample gas travelling from the exhaust runner to the heated line and then to the FID. The fast-FID system addressed this issue by means of remote FID head with a carefully designed capillary sampling system. As a result the response time was reduced from 1-2 seconds for a conventional device to 1-2 $\mathrm{ms}$ for the fast-FID (the exact value depending on detail of the sampling arrangement). In the present work, the sample probe was placed 20 $\mathrm{mm}$ downstream of one of the two exhaust valves as shown in Figure 2.

The HC concentration in the exhaust port remains significantly high after the exhaust valve is closed. Particularly for a single cylinder engine operating 
with high exhaust back pressure and a surge tank, the exhaust gas is likely to reside in the manifold after EVC (exhaust valve closure). As a result, the initial fast FID signal level at EVO (exhaust valve opening) starts from the value it had at EVC of the previous cycle. This potential drawback can be overcome by skip-firing, as in the case of Colban and co-workers [13] who illustrated the effect of injection timing sweeps on HC emissions sources. Skip-firing ensures that there is no residual $\mathrm{HC}$ remaining in the exhaust port prior to the fired cycle where $\mathrm{HC}$ behaviour is of interest. However, skip-firing is not a viable strategy for the present study, which uses real EGR (as opposed to simulated EGR using inert gases). The high exhaust back-pressure required to drive the high EGR necessary for our LTC strategy results in high levels of residuals both in the cylinder and in the exhaust port. Although this may offer a more 'realistic' representation of the $\mathrm{HC}$ characteristics in LTC conditions, it also diminishes our ability to resolve $\mathrm{HC}$ behaviour and relationships within an isolated combustion cycle as expertly carried out in the referenced study.

\section{Test plan}

A series of tests were carried out to understand the impact of variations in intake manifold induced swirl ratio on the combustion characteristics of known LTC conditions. The test conditions investigated are shown in Table 2. The three AVL swirl ratio settings examined, $0.76,1.33$, and 2.43 , correspond respectively to the following tangential and helical port throttle settings: the tangential port fully open with the helical port $50 \%$ closed, both ports fully open, and the tangential port fully closed with the helical port $50 \%$ open as was shown schematically in Figure 1.

\section{Results and discussion}

In the first results subsection, we present an analysis of the effect of intake-throttle induced swirl on a single injection, 3 bar GIMEP condition. As the emis- sions mechanisms for low load LTC are well known, these results provide a foundation for understanding how swirl can be used to navigate a route to improved combustion efficiency in LTC. Subsequent subsections contain an examination of the effects of swirl on emissions at the 6 bar GIMEP condition. Note that where fast-FID results are shown, each FID trace has been shifted such that the initial response of the probe corresponds with exhaust valve opening (EVO) timing.

\subsection{Condition I: 3 bar GIMEP nomi- nal $(0.36 \mathrm{~kg} / \mathrm{hr}$ fuel $), 15.5 \% \mathrm{Y}_{\mathrm{O} 2}$, $\mathrm{SOI}=7.5 \mathrm{BTDC}$}

This test condition had been used by the authors in a prior investigation into fuel oxygenation effects where it was found to have a high combustion efficiency $(\sim 97 \%)$ with no real bias in the fast FID signal for cycle resolved hydrocarbon sources [14]. It was expected that by varying swirl levels in this well understood highly premixed condition the combustion event would be perturbed in such a way as to provide a better understanding of the mechanisms of UHC production in LTC. Note that in this work we define LTC as occurring when NOx and smoke values are simultaneously near zero (arbitrarily set at $<20$ ppm NOx and $<1$ FSN smoke) regardless of dilution or combustion behaviour.

Figure 3 shows the variation of apparent (net) heat release rate (AHRR) with crank angle and AVL swirl

Table 2: Engine operating conditions for LTC

\begin{tabular}{lcc}
\hline Condition & $\mathrm{I}$ & $\mathrm{II}$ \\
\hline Engine speed & $1500 \mathrm{r} / \mathrm{min}$ & $1500 \mathrm{r} / \mathrm{min}$ \\
Nominal load & $3 \mathrm{bar} \mathrm{GIMEP}$ & $6 \mathrm{bar} \mathrm{GIMEP}$ \\
AVL Swirl Ratio, Rs & $0.76,1.33,2.43$ & $0.76,1.33,2.43$ \\
Fuelling & $0.36 \mathrm{~kg} / \mathrm{hr}$ & $0.72 \mathrm{~kg} / \mathrm{hr}$ \\
Fuel pressure & $90 \mathrm{MPa}$ & $90 \mathrm{MPa}$ \\
Injection timing & $7.5 \mathrm{CA} \mathrm{BTDC}$ & $30 \mathrm{CA} \mathrm{BTDC}$ \\
Injection mode & $\mathrm{Single}$ & Single \\
Intake pressure & $120 \mathrm{kPa}$ & $150 \mathrm{kPa}$ \\
Intake mole fraction, $\mathrm{O}_{2}$ & $15.5 \%$ & $10 \%$ \\
Intake charge temp. & $330 \mathrm{~K}$ & $345 \mathrm{~K}$ \\
\hline
\end{tabular}



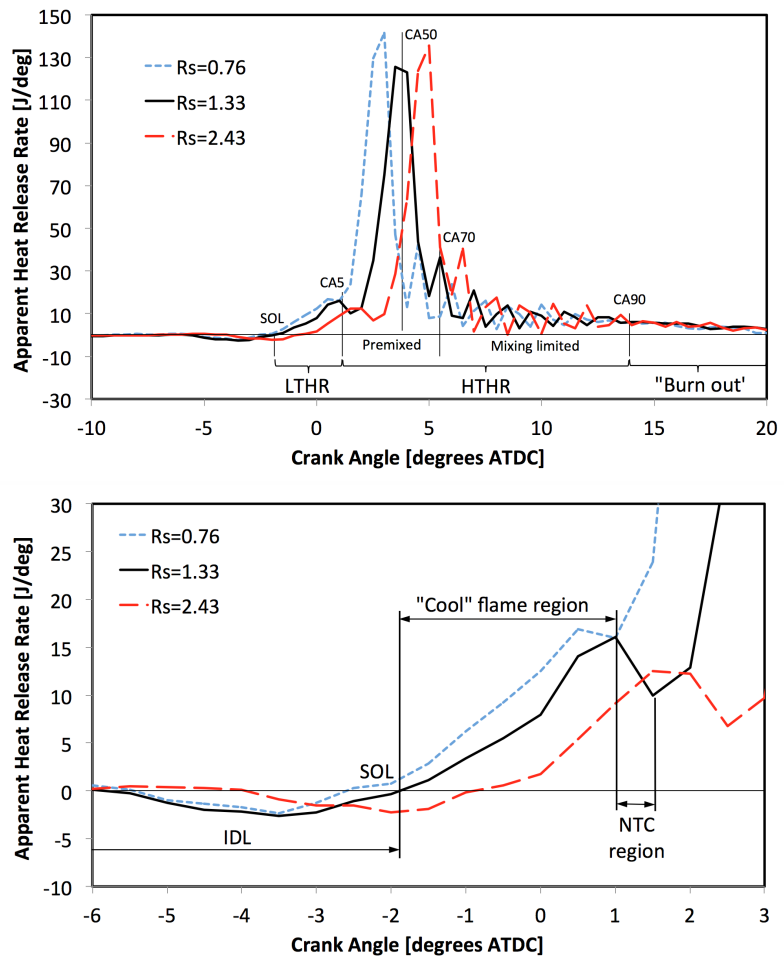

Figure 3: Variation of apparent (net) heat release rate with crank angle for the 3 bar GIMEP nominal (0.36 kg/hr fuel), $15.5 \% \mathrm{Y}_{O 2}$, SOI $=7.5 \mathrm{BTDC}$ condition and AVL swirl ratios of 0.76, 1.33, and 2.43, (Upper image: HTHR and LTHR regions, lower image: detail of LTHR region). ratio for the 3 bar GIMEP condition (Condition 1). The AHRR was calculated according to Equation (1) using a three point central differencing scheme for the numerical differentiation.

$$
\text { AHRR }=\frac{\gamma}{\gamma-1} p \frac{\mathrm{d} V}{\mathrm{~d} \theta}+\frac{1}{\gamma-1} V \frac{\mathrm{d} p}{\mathrm{~d} \theta}
$$

where $p$ is the cylinder pressure, $V$ is the cylinder volume, $\theta$ is the crank angle, and $\gamma$ is the specific heat ratio (assumed to be constant at 1.29).

The oscillatory behaviour seen in the data after the peak heat release rate (Figure 3, upper graph) has been shown to be a characteristic of low to intermediate EGR rate diesel combustion due to the rapid pressure rise associated with a significant pre-mixed combustion phase. These oscillations, which are sensitive to both the numerical differentiation scheme and the data resolution, are not seen at high-EGR LTC conditions where the pressure rise rate is limited by oxygen availability [15].

For all three swirl ratios, the AHRR is characterised by a distinct low temperature heat release (LTHR) region as detailed in the lower graph of Figure 3. This LTHR region is followed by a region of rapid high temperature heat release (HTHR) corresponding to combustion of the premixed fraction of the charge and then by a significantly slower mixinglimited heat release phase as the in-cylinder charge begins to cool with expansion. As shown in Figure 3, and following the work of Cong et al. [16], we define the start of LTHR (SOL) as the crank angle where the heat release rate is first positive (corresponding to the minimum value of the integrated heat release curve), and the ignition ignition delay of the low temperature heat release (IDL), as the duration from start of fuel injection to SOL. The duration of the low temperature phase of combustion (DurL) is then defined as the the duration between SOL and the $5 \%$ heat release crank angle (CA5). Thus, CA5 is taken to indicate the start of the high temperature combustion period $(\mathrm{SOH})$ and the ignition delay to the start of HTHR (IDH) is SOH - SOI. Combustion phasing is described by the $50 \%$ heat release crank angle (CA50) and the mixing-limited HTHR phase by the interval between the $70 \%$ heat release crank angle (CA70) and the $90 \%$ heat release crank angle (CA90). Note the 
majority of the combustion event at this condition is expected to occur in the premixed regime, thus we define the premixed phase of the HTHR by CA70-CA5. The high temperature combustion duration (DurH) is defined as CA90 - CA5.

Figure 4 shows the normalised, cumulative heat release derived data for the individual swirl ratio cases. The data represents the average values from $200 \mathrm{cy}-$ cles. As per Stone [17], the $100 \%$ heat release crank angle (CA100) is given as an alternative marker for the end of combustion. For this, highly premixed condition, the data shows that increasing the AVL swirl ratio from $R_{s}=0.76$ to $R s=2.43$ increases the ignition delays for both the LTHR and HTHR by approximately $2 \mathrm{CA}$ degrees. Both the low and high temperature combustion durations are essentially unchanged and there is no observable change in the balance of premixed to mixing-limited combustion. Thus, at first glance, it would appear that there is no swirl ratio effect on this operating strategy. However, this is not necessarily the case.

When assessing these results for causal effect it is important to recognise that varying swirl ratio by throttling the intake ports necessarily changes volumetric efficiency and affects the temporal development of in-cylinder pressure and temperature. Thus, while results in this work are typically presented in terms of a response to a variation of swirl ratio, the results are a response to a change in intake port flow resistance and that, accordingly, the effects of swirl are often confounded with those of charge mass, temperature and pressure. With this in mind, Table 3 details the variation of measured and derived incylinder pressures, temperatures, charge masses and densities at the start of fuel injection (SOI) for all three swirl ratios at this test point. Figure 5 details the temporal development of the pressure and temperature through the cycle.

It is interesting to note that the charge temperature, calculated assuming ideal gas behaviour from the measured cylinder pressure, air, fuel and EGR mass flow rates and the cylinder volume, is $\sim 130 \mathrm{~K}$ higher at SOI for the elevated swirl ratio condition $(\mathrm{Rs}=2.43)$. This corresponds to an increase of incylinder charge temperature at IVC of approximately 60 K. Note that Table 4 shows a similarly increased
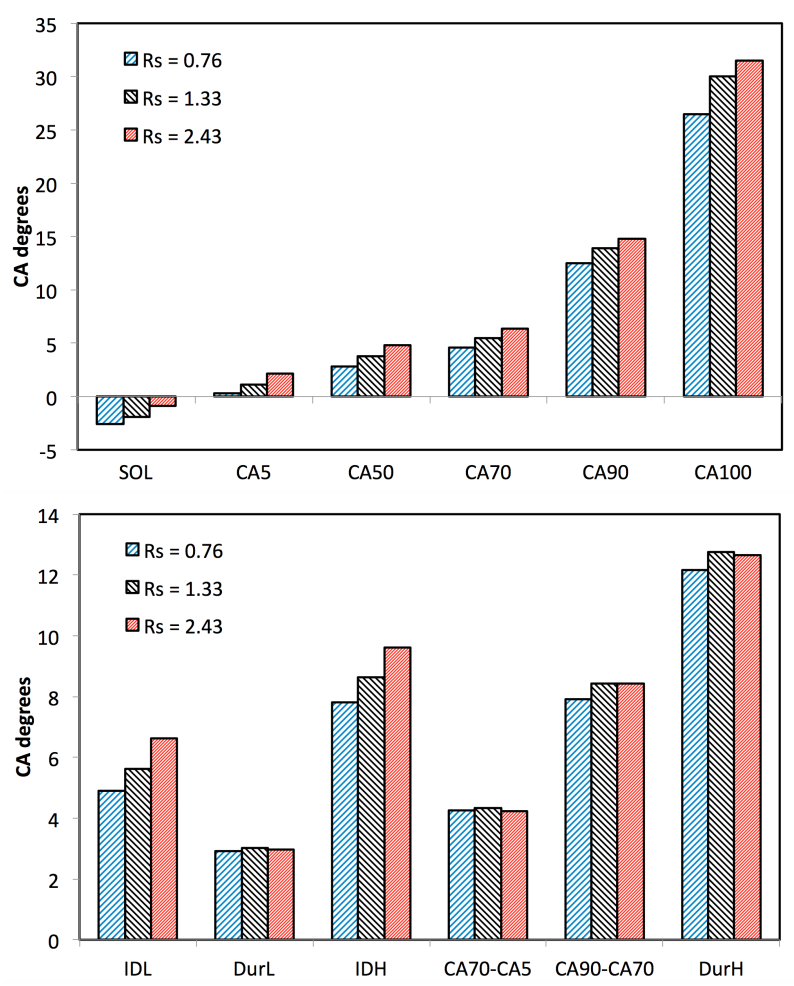

Figure 4: Cumulative heat release derived combustion metrics for the 3 bar GIMEP nominal (0.36 $\mathrm{kg} / \mathrm{hr}$ fuel $), 15.5 \% \mathrm{Y}_{\mathrm{O} 2}$, SOI $=7.5 \mathrm{BTDC}$ condition and AVL swirl ratios of $0.76,1.33$, and 2.43

Table 3: Variation of in-cylinder properties at SOI with swirl ratio for the 3 bar GIMEP nominal $(0.36 \mathrm{~kg} / \mathrm{hr}$ fuel), $15.5 \% \mathrm{Y}_{\mathrm{O} 2}$, SOI $=7.5 \mathrm{BTDC}$ condition

\begin{tabular}{ccccc}
\hline $\begin{array}{c}\text { Swirl ratio } \\
(-)\end{array}$ & $\begin{array}{c}\text { Pressure } \\
(\text { bar })\end{array}$ & $\begin{array}{c}\text { Trapped mass } \\
(\mathrm{g})\end{array}$ & $\begin{array}{c}\text { Temp. } \\
(\mathrm{K})\end{array}$ & $\begin{array}{c}\text { Density } \\
\left(\mathrm{kg} \cdot \mathrm{m}^{-3}\right)\end{array}$ \\
\hline 0.76 & 46.16 & 0.636 & 856 & 18.39 \\
1.33 & 42.35 & 0.595 & 858 & 17.20 \\
2.43 & 39.77 & 0.476 & 984 & 13.76 \\
\hline
\end{tabular}




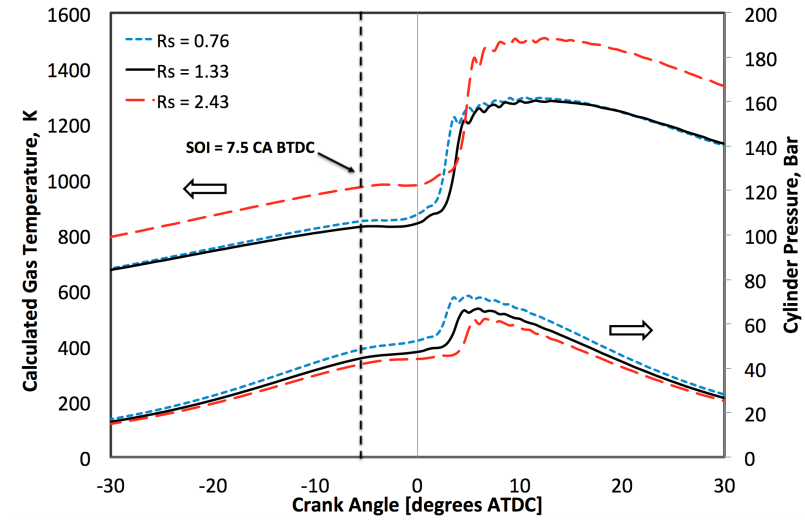

Figure 5: In-cylinder pressure and calculated bulk gas temperature for the 3 bar GIMEP nominal $(0.36$ $\mathrm{kg} / \mathrm{hr}$ fuel), $15.5 \% \mathrm{Y}_{\mathrm{O} 2}$, SOI $=7.5 \mathrm{BTDC}$ condition and AVL swirl ratios of $0.76,1.33$, and 2.43

charge temperature at the 6 bar GIMEP high swirl ratio, $\mathrm{Rs}=2.43$, condition. The authors attribute the increase of charge temperature at SOI to the substantial level of port throttling used to generate the higher swirl ratio. Intake throttling in diesel engines has been shown to slow combustion and consequently to increase exhaust temperature [18] - both of these effects are observed in this work where exhaust temperature is increased by approximately $20 \mathrm{~K}$ when moving between the low and high swirl conditions. It is suggested that the temperature of the residual gases in the cylinder is similarly increased while the incoming, cooler, charge mass - which is controlled to the values given in Table 1 - is reduced, leading to the observed net increase in temperature. Note that with respect to changes in wall-heat transfer, the inhibiting effect of reduced charge mass will act against the promoting effect of increased swirl motion.

Returning to the results presented in Figure 4, ignition delay is shown to increase monotonically with increasing swirl ratio. This is an interesting result in light of the greatly elevated in-cylinder temperature for the high swirl ratio condition. The experimental works of Benajes et al. [19], and Picket et al. [20] correlate diesel ignition delay (IDL and IDH) with an
Arrhenius type equation of the form,

$$
\mathrm{ID} \propto \exp \left(\frac{E}{R T_{a m b}}\right) \rho_{a m b}^{a} \Delta p_{n o z}^{b} O_{2} \%^{c}
$$

where $E$ is the global activation energy $\left(\mathrm{kJ} \cdot \mathrm{mol}^{-1}\right.$ ), $R$ is the universal gas constant $\left(\mathrm{kJ} \cdot \mathrm{mol}^{-1} \cdot \mathrm{K}^{-1}\right), T_{a m b}$ is the ambient gas temperature $(\mathrm{K}), \rho_{a m b}$ is the ambient gas density $\left(\mathrm{kg} \cdot \mathrm{m}^{-3}\right), \Delta p_{\text {noz }}$ is the pressure difference between fuel rail and the ambient gas (MPa), $\mathrm{O}_{2} \%$ is the volumetric oxygen concentration in the ambient gas (\% vol.), and the empirical constants in the equation are given in the ranges of 6534 to 7523 for $\mathrm{E} / \mathrm{R},-1.35$ to -0.96 for exponent $a,-0.09$ to 0 for $b$, and -0.51 to -1 for $c$.

Following Equation 2, high temperature ignition delay is expected to be a strong negative function of temperature and oxygen concentration (where both factors are directly related to the combustion chemistry) and ambient density (which significantly influences spray break-up and atomization [21]), while being relatively insensitive to pressure. Using the values of temperature, pressure, and gas density given in Table 3 with the constant $\mathrm{E} / \mathrm{R}$ adjusted so that the results are matched to the low swirl ratio $(\mathrm{Rs}=0.76)$ condition, the correlation of Benajes and co-workers accurately predicts the observed increase in high temperature ignition delay at the mid-swirl level (Rs=1.33). Thus, it might be considered that the changes in combustion behaviour observed between the low- and mid- swirl ratio cases are consistent with the reduction of charge density caused by the throttling effect of swirl flap operation and that the effect of the changing swirl levels between these conditions is not significant.

However, the high swirl ratio $(\mathrm{Rs}=2.43)$ operating condition is characterised by significantly increased charge temperature at SOI (c.f. Table 3) and for this condition Benajes' correlation predicts an approximate 5 degree CA reduction in high temperature ignition delay as opposed to the experimentally observed increase of 1 degree $\mathrm{CA}$. The departure of the experimental results for ignition delay from the predicted trend at this high-swirl, high temperature condition suggests that either the reduction of charge density associated with the throttling effect of the swirl valves 


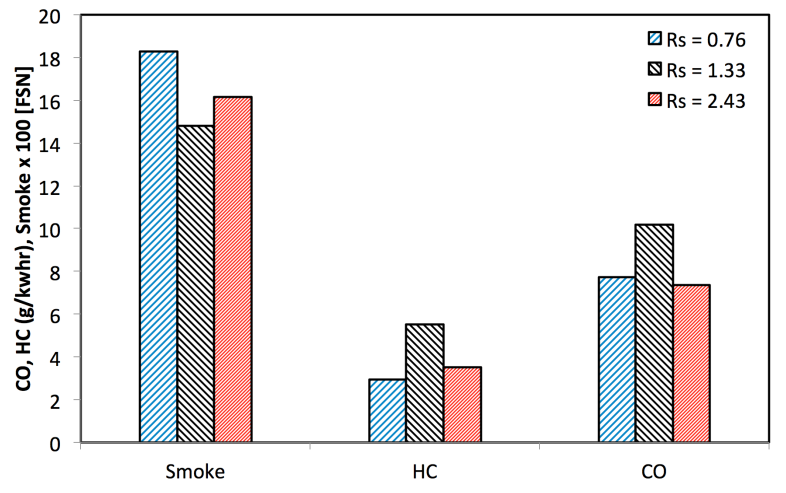

Figure 6: Smoke, HC and CO emissions for the 3 bar GIMEP nominal $(0.36 \mathrm{~kg} / \mathrm{hr}$ fuel $), 15.5 \% \mathrm{Y}_{\mathrm{O} 2}$, SOI $=7.5$ BTDC condition and AVL swirl ratios of 0.76, 1.33 , and 2.43

is such that the density is outside of the density limits of the empirical correlation or that, as the authors will argue, the increased levels of swirl have a significant negative effect on ignition delay in addition to the expected density effect.

Considering the data shown in the lower image of Figure 3, it is clear that, despite there being a significantly higher in-cylinder temperature and lower charge density at SOI - both factors that should theoretically increase vaporisation rates - the evaporation process (negative heat release rate) starts later for the high swirl condition than is the case for the two lower swirl ratios. It is postulated that the cause of the delayed evaporation, and the associated increased lowand high-temperature ignition delay (IDL and IDH, c.f Figure 4), for the $\mathrm{Rs}=2.43$ test point is an increase in wall heat transfer rate and more effective convection of heat away from the evaporating and reacting fuel-air mixture in the piston bowl due to increased swirl motion [22].

Figure 6 details the variation of smoke, $\mathrm{HC}$, and $\mathrm{CO}$ emissions with swirl number. The smoke emissions are uniformly low at this condition $(\mathrm{FSN}=0.18$, 0.14 and 0.16 ) and it is not considered that the observed changes are statistically significant. With regard to the $\mathrm{HC}$ and $\mathrm{CO}$ emissions, Figure 7 shows mean cycle resolved hydrocarbon emissions for the

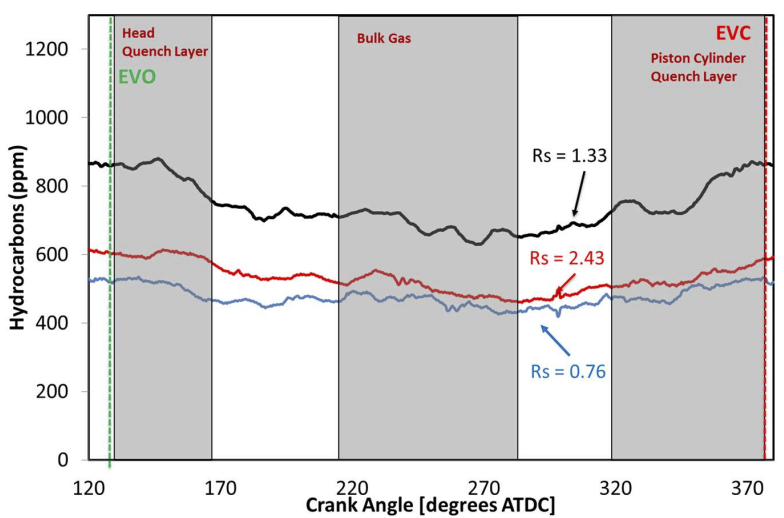

Figure 7: Mean fast FID traces for the 3 bar GIMEP nominal $(0.36 \mathrm{~kg} / \mathrm{hr}$ fuel $), 15.5 \% \mathrm{Y}_{O 2}$, SOI $=7.5$ BTDC condition and AVL swirl ratios of $0.76,1.33$, and 2.43

three swirl ratios measured by the fast FID. The cycle resolved data measured by the fast FID are in good agreement with the 200 cycle averaged data presented in Figure 6 giving confidence to the observed trends, i.e. that as the swirl ratio is increased from 0.76 to $1.33 \mathrm{HC}$ emissions increase and then decrease as the swirl ratio is increased from 1.33 to 2.43 . As expected, the $\mathrm{CO}$ emissions follow the same trend.

Magnitude aside, the shapes of the fast FID data shown in Figure 7 for the three different swirl ratios are very similar indicating that neither the variation of swirl nor the port-throttle induced changes of incylinder pressure, temperature and density substantially alter the HC sources at this load point. The robustness of the operating strategy in this regard is attributed to the relatively late injection (SOI $=-7.5$ degrees ATDC) timing that ensures that the injected fuel is fully contained within the combustion bowl [9]. With regard to the cycle average $\mathrm{HC}$ emissions behaviour, for a fixed oxygen concentration and fuelling, throttling the intake ports in order to increase swirl will reduce the trapped mass and hence increase the global equivalence ratio in-cylinder. It is possible that the increase in $\mathrm{HC}$ and $\mathrm{CO}$ that is observed when moving from the $\mathrm{Rs}=0.76$ swirl ratio to the $\mathrm{Rs}_{\mathrm{s}}=1.33$ swirl ratio is due to this effect - note that 
the calculated in-cylinder temperatures are very similar for these two cases. For the high swirl, $\mathrm{Rs}=2.43$, case - which is highly throttled - it is possible that this reduced oxygen is availability offset by the higher in-cylinder temperature noted in Figure 5.

\subsection{Condition II: 6 bar GIMEP nomi- nal $\left(0.72 \mathrm{~kg} / \mathrm{hr}\right.$ fuelling), $10 \% Y_{O 2}$, $\mathrm{SOI}=30 \mathrm{BTDC}$}

With respect to Condition I, Condition II is characterised by a higher load, significantly advanced fuel injection timing and a greatly reduced intake oxygen concentration. Intake manifold pressure is also increased compared to Condition I.

The trends observed with respect to the variation of low and high temperature heat release (Figure 8), and combustion phasing and duration (Figure 9) with increasing AVL swirl ratio differ markedly from those at the 3 bar GIMEP condition. Whereas combustion phasing was generally retarded with increasing swirl ratio conditions for the 3 bar GIMEP condition, combustion phasing is advanced with increasing swirl ratio at the 6 bar GIMEP condition. Recognising as before the potential significance of port-throttling effects, Table 4 details the in-cylinder pressure, temperature, trapped mass, and charge density at SOI for each of the swirl ratio settings. The temporal development of the pressure and temperature through the cycle is shown in Figure 10. Note that the advanced fuel injection timing at this condition reduces both pressure and temperature at SOI compared to Condition I despite the higher load. Also, whilst the throttling effect of the tangential and helical port settings for the generation of different swirl levels is still evident, the magnitude of the density change between the high and low swirl cases is much reduced.

Analysis of the heat release derived data shows that both the low and high temperature ignition delays, IDL and IDH, decrease monotonically as the swirl ratio increases from $\mathrm{Rs}=0.76$ to $\mathrm{Rs}=2.43$. Comparing this behaviour to that predicted by the correlations of Benajes et al. [19] and Pickett et al. [20] shows the experimental data to conform to the expected trend; however, the magnitude of reduction in ignition delay
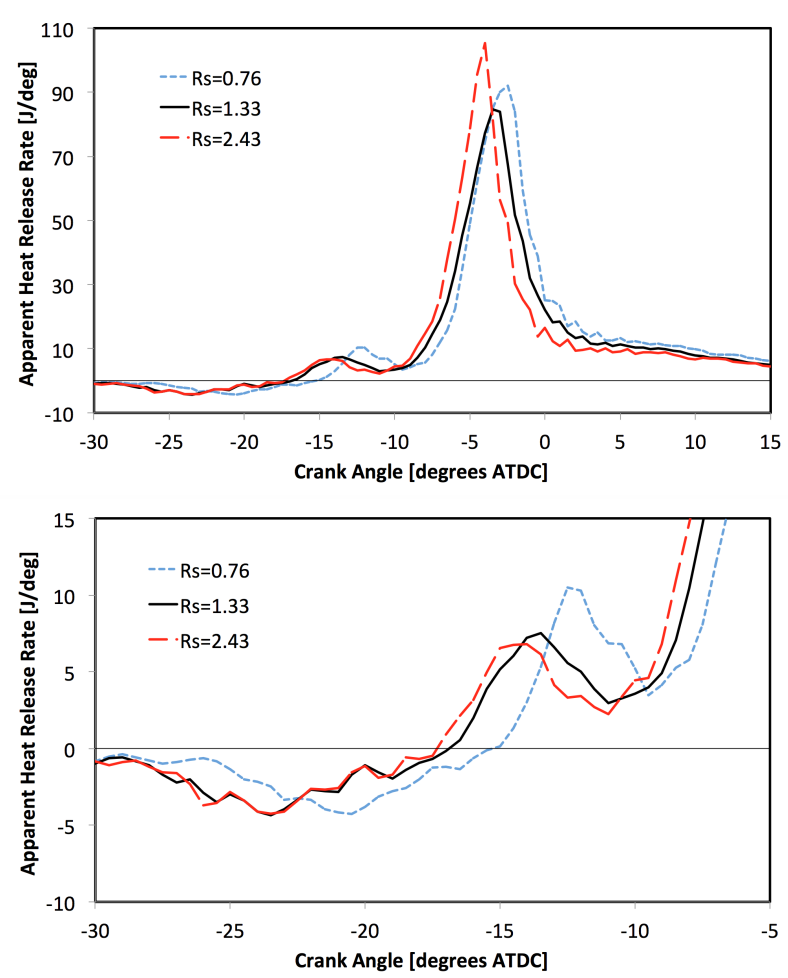

Figure 8: Variation of apparent heat release rate with crank angle for the 6 bar GIMEP nominal $(0.72 \mathrm{~kg} / \mathrm{hr}$ fuel), $10 \% \mathrm{Y}_{\mathrm{O} 2}$, SOI $=30 \mathrm{BTDC}$ condition and AVL swirl ratios of $0.76,1.33$, and 2.43, (Upper image: LTHR and HTHR regions, lower image: detail of LTHR region)

Table 4: Variation of in-cylinder properties at SOI with swirl ratio for the 6 bar GIMEP nominal $(0.72 \mathrm{~kg} / \mathrm{hr}$ fuel), $10 \% \mathrm{Y}_{\mathrm{O} 2}, \mathrm{SOI}=30 \mathrm{BTDC}$ condition

\begin{tabular}{ccccc}
\hline $\begin{array}{c}\text { Swirl ratio } \\
(-)\end{array}$ & $\begin{array}{c}\text { Pressure } \\
(\text { bar })\end{array}$ & $\begin{array}{c}\text { Trapped mass } \\
(\mathrm{g})\end{array}$ & $\begin{array}{c}\text { Temp. } \\
(\mathrm{K})\end{array}$ & $\begin{array}{c}\text { Density } \\
\left(\mathrm{kg} \cdot \mathrm{m}^{-3}\right)\end{array}$ \\
\hline 0.76 & 23.03 & 0.710 & 720 & 10.67 \\
1.33 & 22.02 & 0.647 & 758 & 9.26 \\
2.43 & 21.30 & 0.566 & 824 & 8.85 \\
\hline
\end{tabular}



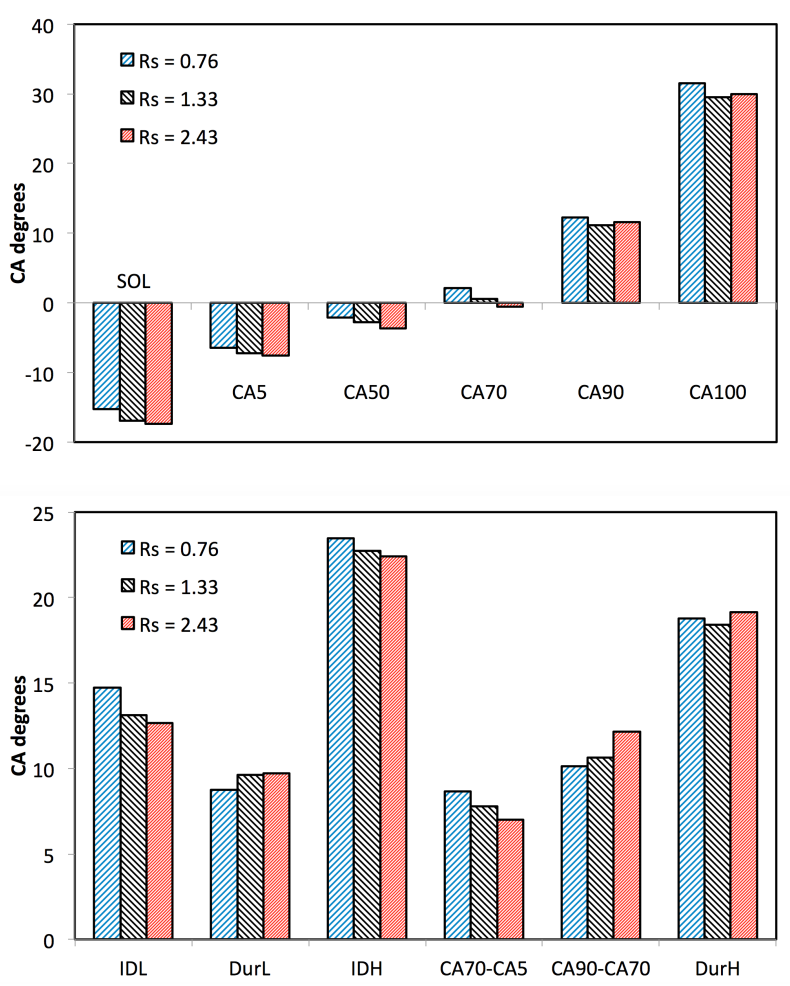

Figure 9: Cumulative heat release derived combustion metrics for the 6 bar GIMEP nominal (0.72 $\mathrm{kg} / \mathrm{hr}$ fuel), $10 \% \mathrm{Y}_{\mathrm{O} 2}$, SOI $=30 \mathrm{BTDC}$ condition and AVL swirl ratios of $0.76,1.33$, and 2.43

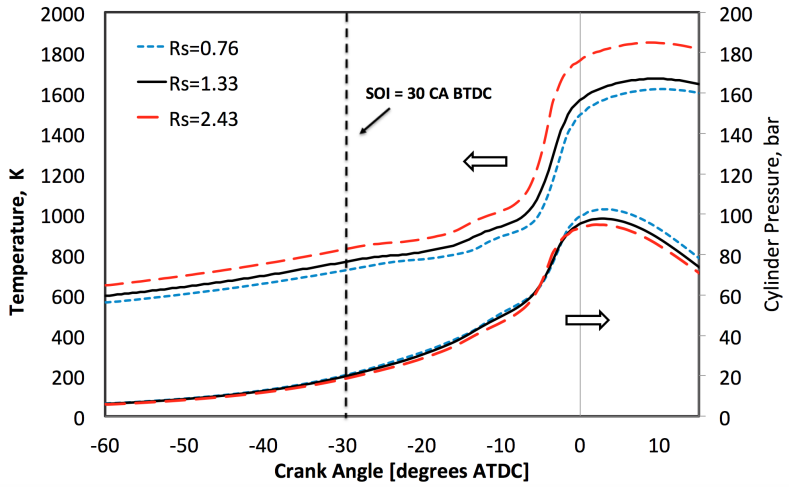

Figure 10: In-cylinder pressure and calculated bulk gas temperature for the 6 bar GIMEP nominal ( 0.72 $\mathrm{kg} / \mathrm{hr}$ fuel), $10 \% \mathrm{Y}_{\mathrm{O} 2}$, SOI $=30 \mathrm{BTDC}$ condition and AVL swirl ratios of $0.76,1.33$, and 2.43

that is predicted by the correlation is substantially greater than that observed experimentally. Of particular note within these results is that the premixed combustion duration (CA70 - CA5) is decreased as the swirl ratio is increased and that the late cycle mixing-limited burn duration (CA90 - CA70) is increased with increasing swirl. Note also that maximum heat release rate occurs at the high swirl condition.

Although, Miles [2] reported a reduction in the premixed burn fraction and peak heat release with increasing swirl - attributed to reduced ignition delay compensating for the supposed swirl-induced increase in initial fuel/air mixing during the ignition delay period - the majority of the literature suggests that increasing swirl leads to increased premixed burn fractions and peak heat release rates as a result of enhanced premixing efficacy [23]. Of particular relevance within the literature is an optical and numerical study on high-dilution LTC diesel combustion, i.e. a similar operating strategy to Condition II of the present work, by Kook et al. [5] who report similar combustion trends as observed in the present work. Specifically that for fixed injection timing, increasing swirl levels lead to reduced ignition delay, advanced combustion phasing for the early (premixed) phase of heat release and an increase in peak heat release val- 


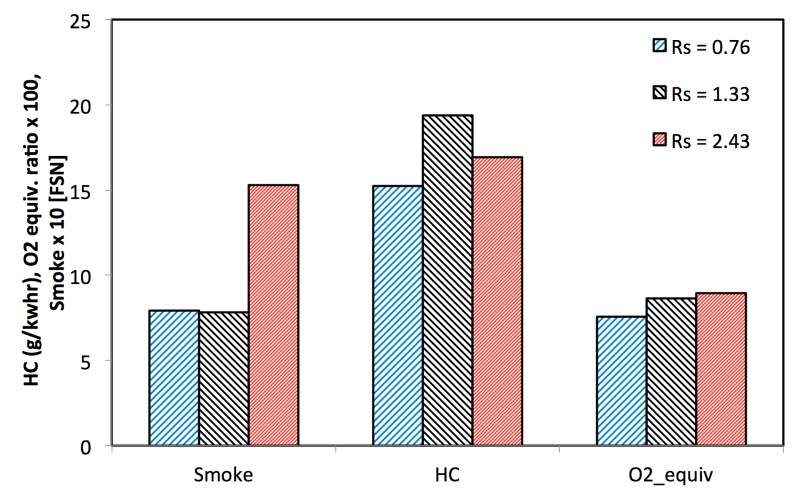

Figure 11: Smoke and $\mathrm{HC}$ emissions and $\mathrm{O}_{2}$ equivalence ratios for the 6 bar GIMEP nominal $(0.72 \mathrm{~kg} / \mathrm{hr}$ fuel), $10 \% \mathrm{Y}_{\mathrm{O} 2}$, SOI $=30 \mathrm{BTDC}$ condition and AVL swirl ratios of $0.76,1.33$, and 2.43

ues. The similarity between the results of the present study and the results of Kook [5] in this regard suggest that the throttling effects associated with swirl generation in the present work, and in particular the reduction of charge density, do not have a dominant effect on the heat release behaviour in this operating mode. However, it does seem likely that the throttling effects, and in particular the raised in-cylinder temperature at the high swirl condition, directly influence emissions.

Figure 11 details the variation of smoke and HC emissions with swirl number. $\mathrm{CO}$ emissions are not shown here as exhaust $\mathrm{CO}$ for this condition is beyond the scale of the Horiba Mexa 7100 HEGR analyser. Figure 12 details the cycle resolved HC emissions for the $\mathrm{Rs}_{\mathrm{s}}=0.76$ and $\mathrm{Rs}=1.33$ swirl ratios. Unfortunately, it was not possible to record the fast FID signal at the $\mathrm{Rs}=2.46$ swirl ratio due to the high exhaust smoke output at this condition which had the potential to damage the HFR 400 fast FID and corrupt results. Again the trends of the fast FID data are in good agreement with the 200 cycle averaged data shown in Figure 11.

Accepting that the heat release results at this condition are a strong indicator of enhanced premixing with increasing swirl ratio even as the charge density is decreased, then the smoke and hydrocarbon

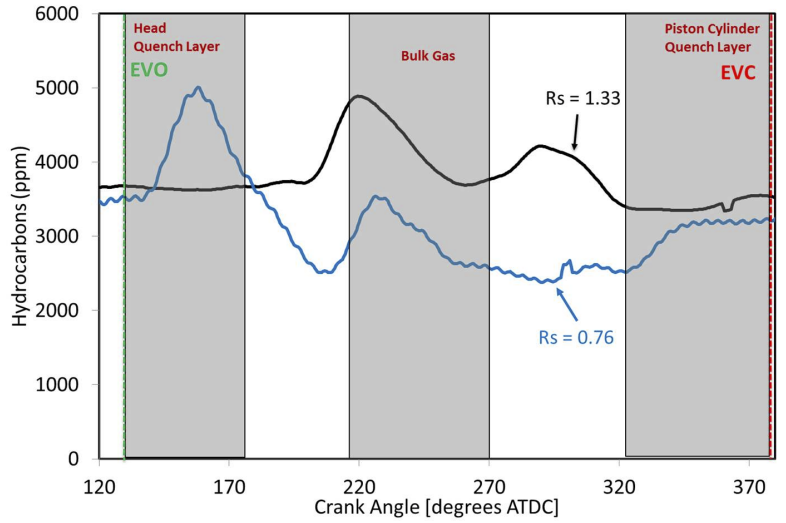

Figure 12: Mean fast FID traces for the 6 bar GIMEP nominal $(0.72 \mathrm{~kg} / \mathrm{hr}$ fuel $), 10 \% \mathrm{Y}_{O 2}$, SOI $=30 \mathrm{BTDC}$ condition and AVL swirl ratios of 0.76 and 1.33. No fast FID data was collected at $\mathrm{Rs}=2.43$ due to the high soot emissions associated with this test point.

emissions shown in Figure 11 are informative. Smoke emissions, relatively constant at approximately 0.8 FSN as the swirl ratio is increased from $\mathrm{Rs}=0.76$ to Rs=1.33, almost double to $1.53 \mathrm{FSN}$ at the higher $(\mathrm{Rs}=2.43)$ swirl ratio. Hydrocarbon emissions initially increase with increasing swirl before falling back slightly at the highest swirl ratio condition. We suggest that these results are consistent with the increasing confinement of fuel to the central region of the combustion chamber with increasing swirl as reported by Auriemma et al. [24]. Engine-out soot emissions are the net result of competing in-cylinder formation and oxidation processes. While premixing in the central region of the cylinder would be increased at the high swirl condition, the expected enrichment of the central region and the possible formation of rich mixture pockets would likely lead to an increase in soot production. Moreover, it is also considered possible that the subsequent oxidation process will be compromised due to the swirl-induced trapping of the soot mass within the bowl as predicted by Genzale and co-workers [25]. Others have observed soot precursors generally forming in the bowl / central region at similar conditions, with leaner mixtures being more prevalent in the squish area [26, 27]. 
The fast FID data shown in Figure 12 provides further evidence for the swirl-induced confinement of fuel and combustion products at this operating condition. In contrast to the fast FID data that was presented for the lower-load, partially-premixed, Condition I, the temporal evolution of the $\mathrm{HC}$ signal differs substantially for different swirl ratios. A previous work on this engine [9] has shown that for a -30 degree ATDC SOI injection timing there is the strong likelihood that the injected fuel will not be fully contained within the bowl and that some fraction of the fuel will enter the piston squish region. In agreement with [13], the initial spike that is seen in the low swirl, $\mathrm{Rs}=0.76$, data is thought to be associated with $\mathrm{HC}$ emissions from fuel trapped in the squish volume and in quench layers along the head and valve surfaces. Following this initial peak, the HC signal for the low swirl condition falls significantly until approximately 200 degrees ATDC at which point the fast FID HC measurement peaks again as the bulk gas leaves the cylinder. There is a then further distinct rise at approximately 320 degrees ATDC for the low swirl case which is again associated with fuel in the squish volume [13]. It is notable that the fast FID data for the higher swirl ratio case $\left(\mathrm{Rs}_{\mathrm{f}}=1.33\right)$ does not show any evidence of $\mathrm{HC}$ emissions from these two squish region related sources. Given that the injection timing is unchanged and that the differences between the in-cylinder density and the temperature at these two operating conditions are modest (c.f. Table 4) we conclude that the increased swirl level is indeed acting to concentrate the fuel into the central region of the cylinder.

With regard to the emissions data presented in Figure 11, it is clear from Figure 12 that the increase in cycle averaged HC emissions for the mid-swirl ratio, $\mathrm{Rs}=1.33$, operating point is attributable to a substantially greater level of $\mathrm{HC}$ in the bulk gas compared with the lower swirl ratio $\mathrm{Rs}=0.76$, condition. This implies an increase in unburned hydrocarbons from sources within and above the piston bowl. The oxygen equivalence ratio at this condition $\left(\phi_{\mathrm{O} 2}=0.8\right)$ is such that it seems unlikely that these $\mathrm{HC}$ (and $\mathrm{CO}$ ) emissions would originate solely from over-mixed regions of the charge. It is then suggested that, despite the acknowledged enhancement of the early pre- mixing process, the swirl induced enrichment of the central region of the cylinder results in an increased number of locally rich pocket of mixture thereby increasing $\mathrm{HC}$ emissions at this swirl ratio, $\mathrm{Rs}=1.33$.

It is to be expected that this effect would be the most severe for the highest swirl condition $(\mathrm{Rs}=2.43)$ which, despite having the same intake oxygen concentration as the lower swirl test points, has an increased global equivalence ratio due to its substantial portthrottle induced reduction in volumetric efficiency. The experimental results show an unexpected fall in $\mathrm{HC}$ emissions at the highest swirl condition. The cause of this reduction is not understood and the high smoke emissions found this swirl ratio and operating point preclude the use of the fast FID. It is possible that the high smoke emissions may act as a partial substitute for the $\mathrm{HC}$ emissions as well as reducing detected $\mathrm{HC}$ via absorption of soluble organic fractions. Another possible explanation for the observed reduction in $\mathrm{HC}$ emissions could be higher bulk in-cylinder temperatures as shown in Figure 10 combined with the extended mixing controlled phase of combustion (Figure 9). Further investigation of this point is required.

\subsection{Conclusions}

The purpose of this study was to explore the potential benefits of enhanced mixing in LTC via variation of the induced swirl flow. This was in order to examine two major challenges in Low Temperature Combustion; (i) the persistence of $\mathrm{HC}$ (and $\mathrm{CO}$ ) at low and medium load conditions, and (ii) the relatively small operational envelope for the LTC mode.

Two LTC strategies were investigated at an engine speed of $1500 \mathrm{r} / \mathrm{min}$ : a low load (3 bar GIMEP) partially premixed strategy with relatively late injection and a $15.5 \%$ oxygen concentration and, a low-medium load (6 bar GIMEP), highly-dilute early injection strategy with $10 \%$ oxygen concentration. Each LTC strategy was tested at three AVL swirl ratio levels $(0.76,1.33$, and 2.43$)$ set by independently throttling the tangential and helical intake ports - where the range of swirl ratios tested represents the full range of variation available in the experimental set-up and where an increase 
swirl ratio is associated with increase in the overall throttling of the engine and therefore a reduction of volumetric efficiency. Thus, the effects of the induced swirl on the combustion performance and emissions are partially confounded with the effects of the varying in-cylinder charge mass, pressure and density. Of particular note in this regard is a substantial $(\sim 110-130 \mathrm{~K})$ increase in charge temperature at SOI associated with the highest swirl ratio settings. This increase, which was noted for both operating strategies, was attributed to higher exhaust temperature and a reduced incoming charge mass. The key findings of the work are summarised as follows:

For the 3 bar GIMEP nominal load condition (late injection, $15.5 \%$ oxygen concentration)

- Ignition delay increased with increasing swirl ratio. For the low- and mid- swirl ratio cases, this increase was consistent with the expected effect of reducing charge density suggesting little or no swirl effect. However, at the highest swirl ratio setting the results suggest that swirl plays a dominant role in controlling ignition delay - offsetting the throttling induced increase in charge temperature by increasing wall heat transfer and heat convection away from the reaction zone.

- Premixed and mixing-controlled combustion durations, defined by CA70-CA5 and CA90-CA70 respectively, were effectively constant for all swirl ratio settings. Thus, increasing swirl ratio retarded the total combustion event in proportion to the increased ignition delay.

- Increasing swirl ratio did not influence the sources of $\mathrm{HC}$ emissions. The robustness of this operating strategy in this regard was attributed to the physical confinement of the injected fuel in the combustion bowl resulting from the relatively late injection timing employed.

For the 6 bar GIMEP nominal load condition (early injection, $10 \%$ oxygen concentration)
- Ignition delay reduced with increasing swirl ratio. Also with increasing swirl ratio, the premixed combustion duration (CA70 - CA5) was decreased and the late cycle mixing-limited burn duration (CA90 - CA70) increased. These effects are attributed to swirl enhanced premixing and are assumed to be indicative of the swirl effects dominating the throttling induced changes in charge properties for this highly dilute, early injection LTC strategy.

- HC sources were observed to vary with increasing swirl ratio such that the cycle $\mathrm{HC}$ emissions for the low swirl case showed strong contributions from the squish volume - where it is expected that the early injection timing would result in piston lip impingement and the penetration of fuel into the squish region. These contributions are not seen at the higher swirl ratio. This changing behaviour is attributed to the supposed swirl-induced confinement of the fuel into the central region of the cylinder.

- Soot emissions are substantially increased at the highest swirl ratio. This increase is also attributed the presumed swirl-induced confinement of the fuel which we suggest would both increase soot formation-by enriching the central region of the cylinder (possibly leading to rich mixture pockets within a charge whose equivalence ratio would have been increased by the intake port throttling) - and reduce soot oxidation-by trapping soot mass within the bowl. However, we note that although these suggested mechanisms by which soot is increased are consistent with the observations of some previous researchers [24, 25, 26, 27] they are not confirmed in this engine by optical study. This is a topic of future work.

The results of this work indicate that for highly dilute early-injection LTC there is a point at which improving premixing by increasing the swirl ratio becomes detrimental to combustion and emissions. The results suggest that this may be due to the swirl induced confinement of intermediates and products from the highly premixed combustion phase to the central re- 
gion of the cylinder - thereby diluting an already limited oxygen presence during the subsequent mixing controlled burn. The caveat to this conclusion is that the in-cylinder charge properties were changed by the use of port-throttles to generate different swirl conditions. Thus, the effects of swirl in this work are to some extent confounded with the effects of portthrottling. Future experiments should seek to isolate the effects of swirl by controlling the in-cylinder charge properties to similar levels for all swirl ratios at the start of fuel injection.

\section{References}

[1] Heywood JB. Internal Combustion Engine Fundamentals. McGraw-Hill, New York, 1988.

[2] Miles PC. The influence of swirl on HSDI diesel combustion at moderate speed and load. $S A E$ Technical Paper 2000; 2000-01-1829. DOI:10. 4271/2000-01-1829.

[3] Kimura S, Aoki O, Ogawa H et al. New combustion concept for ultra-clean and high-efficiency small DI diesel engines. SAE Technical Paper 1999; 1999-01-3681. DOI:10.4271/1999-01-3681.

[4] Choi D, Miles PC, Yun H et al. A parametric study of low-temperature, late-injection combustion in an HSDI diesel engine (diesel engines, performance and emissions, thermal efficiency). In The International Symposium on Diagnostics and Modeling of Combustion in Internal Combustion Engines. 6, , pp. 127-134. DOI: 10.1299/jmsesdm.2004.6.127.

[5] Kook S, Bae C, Miles PC et al. The effect of swirl ratio and fuel injection parameters on co emission and fuel conversion efficiency for highdilution, low-temperature combustion in an automotive diesel engine. SAE Technical Paper 2006; 2006-01-0197. DOI:10.4271/2006-01-0197.

[6] Opat R, Ra Y, Krieger R et al. Investigation of mixing and temperature effects on $\mathrm{HC} / \mathrm{CO}$ emissions for highly dilute low temperature combustion in a light duty diesel engine. SAE Tech- nical Paper 2007; 2007-01-0193. DOI:10.4271/ 2007-01-0193.

[7] Sogbesan OM, Davy MH and Garner CP. The potential of fuel metering control for optimising unburned hydrocarbon emissions in diesel low temperature combustion. SAE Technical Paper 2013; 2013-01-0894. DOI:10.4271/2013-01-0894.

[8] Sogbesan O, Davy MH and Garner CP. Insights into the hydrocarbon and carbon monoxide emissions in moderately and highly dilute low temperature combustion. Proceedings of the Institution of Mechanical Engineers, Part D: Journal of Automobile Engineering 2014; 228(11): 1285-1296.

[9] Sarangi AK, Garner CP, McTaggart-Cowan GP et al. Effects of engine operating parameters on diesel low-temperature combustion with split fuel injection. Proceedings of the Institution of Mechanical Engineers, Part D: Journal of Automobile Engineering 2012; 226(9): 1271-1286. DOI:10.1177/0954407012440937.

[10] Sarangi AK, Garner CP, McTaggart-Cowan GP et al. The effects of split injections on high exhaust gas recirculation low-temperature diesel engine combustion. International Journal of Engine Research 2013; 14(1): 68-79. DOI: $10.1177 / 1468087412450987$.

[11] Sarangi AK, Garner CP, McTaggart-Cowan GP et al. Load transient between conventional diesel operation and low-temperature combustion. Proceedings of the Institution of Mechanical Engineers, Part D: Journal of Automobile Engineering 2015; 229(7): 850-865.

[12] $\mathrm{Xu} \mathrm{H}$. Some critical technical issues on the steady flow testing of cylinder heads. SAE Technical Paper 2001; 2001-01-1308. DOI:10.4271/ 2001-01-1308.

[13] Colban WF, Miles PC and Oh S. On the cyclic variability and sources of unburned hydrocarbon emissions in low temperature diesel combustion systems. SAE Technical Paper 2007; 2007-011837. DOI:10.4271/2007-01-1837. 
[14] Sogbesan S. Strategies for reducing hydrocarbon emissions in diesel low temperature combustion. PhD Thesis, Department of Mechanical, Electrical, and Manufacturing Engineering, Loughborough University, UK, 2016.

[15] Cong S. An experimental study of low temperature combustion in a diesel engine. PhD Thesis, Mechanical, Electrical and Manufacturing Engineering, Loughborough University, UK, 2010.

[16] Cong S, McTaggart-Cowan GP, Garner CP et al. Experimental investigation of low temperature diesel combustion processes. Combustion Science and Technology 2011; 183(12): 1376-1400. DOI:10.1080/00102202.2011.600740.

[17] Stone R. Introduction to internal combustion engines. 4th ed. Palgrave Macmillan, 2012. DOI: 10.1007/978-1-137-02829-7.

[18] Mayer A, Lutz T, Lämmle C et al. Engine intake throttling for active regeneration of diesel particle filters. SAE Technical Paper 2003; 200301-0381. DOI:10.4271/2003-01-0381.

[19] Benajes J, Payri R, Bardi M et al. Experimental characterization of diesel ignition and lift-off length using a single-hole ECN injector. Applied Thermal Engineering 2013; 58(1): 554-563. DOI:10.1016/j.applthermaleng.2013.04.044.

[20] Pickett LM, Siebers DL and Idicheria CA. Relationship between ignition processes and the liftoff length of diesel fuel jets. SAE Technical Paper 2005; 2005-01-3843. DOI:10.4271/2005-01-3843.

[21] Naber JD and Siebers DL. Effects of gas density and vaporization on penetration and dispersion of diesel sprays. SAE Technical Paper 1996; 960034. DOI:10.4271/960034.

[22] Leach FC, Davy MH, Weall A et al. Comparing the effect of a swirl flap and asymmetric inlet valve opening on a light duty diesel engine. $S A E$ Technical Paper 2017; 2017-01-2429. DOI:10. 4271/2017-01-2429.
[23] Winterbone D, Yates D, Clough E et al. Combustion in high-speed direct injection diesel enginesa comprehensive study. Proceedings of the Institution of Mechanical Engineers, Part C: Journal of Mechanical Engineering Science 1994; 208(4): 223-240. DOI:10.1243/pime_proc_1994 208_123_02.

[24] Auriemma M, Caputo G, Corcione F et al. Influence of a swirling air flow on an evaporating diesel spray from a common rail injection system under realistic engine conditions. SAE Technical Paper 2007; 2007-24-0021. DOI:10.4271/ 2007-24-0021.

[25] Genzale CL, Reitz RD and Wickman DD. A computational investigation into the effects of spray targeting, bowl geometry and swirl ratio for low-temperature combustion in a heavy-duty diesel engine. SAE Technical Paper 2007; 2007 01-0119. DOI:10.4271/2007-01-0119.

[26] Musculus MP, Miles PC and Pickett LM. Conceptual models for partially premixed lowtemperature diesel combustion. Progress in Energy and Combustion Science 2013; 39(2): 246283. DOI:10.1016/j.pecs.2012.09.001.

[27] Ekoto IW, Colban WF, Miles PC et al. UHC and $\mathrm{CO}$ emissions sources from a light-duty diesel engine undergoing late-injection low-temperature combustion. In ASME 2009 Internal Combustion Engine Division Fall Technical Conference. American Society of Mechanical Engineers, pp. 163-172. DOI:10.1115/icef2009-14030.

\section{Acknowledgements}

The authors would like to acknowledge the support of Steve Horner, Adrian Broster, Dominic McKean and Graham Smith at Loughborough University's Powertrain Laboratory. We would also like to acknowledge the support of the EPSRC (Grant number: $\mathrm{EP} / \mathrm{F} 031351 / 1)$ and the Royal Academy of Engineering. 